\title{
THE SINO-SINGAPORE TIANJIN ECO-CITY: A CASE STUDY OF CHINESE EXPERIMENTAL REGULATORY AND INSTITUTIONAL DEVELOPMENT
}

\author{
S.J.W. GEROE \\ Faculty of Law, La Trobe University, Australia.
}

\begin{abstract}
The Sino-Singapore Tianjin Ecocity (SSTEC) is a large-scale pilot project, trialling innovative approaches in sustainable urban development. To implement its objectives, the SSTEC has been developed as a central element in a matrix of networked institutional relationships. This paper examines the functioning of these institutional interactions, through examination of the development of renewable energy-related initiatives. The salient elements of these interactions relate to consultation and information flows. This is intended to facilitate an empirically based experimental approach to project planning, implementation and review, in terms of the integration of research and implementation experience. Institutional and regulatory development at the SSTEC is evaluated in the context of other Chinese lowcarbon cities and other localised initiatives such as Green Counties and New Energy Demonstration Cities. This evaluation draws on interviews with senior staff members at the SSTEC, and in specialist Chinese renewable energy institutions, as well as scholarly and other literature. While substantial implementation challenges face the SSTEC and other large-scale projects, they are likely to play an instrumental role in scaling-up technologically and financially effective low-carbon solutions in Chinese urban development. Some inefficiencies and failures are to be expected in any experimental approach. These can be put to effective use through an empirical approach to determining best institutional and regulatory practice, in terms of realising China's low-carbon model of sustainable urban development. Keywords: development, experimental, institutions, low-carbon, regulation, renewable energy, sustainable, Tianjin Eco-city, urban.
\end{abstract}

\section{INTRODUCTION}

The Sino-Singapore Tianjin Ecocity (SSTEC) is a large-scale pilot project, trialling innovative approaches in sustainable urban development. Renewable energy and energy efficiencyrelated measures are integral aspects of its strategy of low-carbon development. This paper examines the SSTEC as a case study of China's experimental approach to regulation (including planning), institutions and projects. Thus it examines the SSTEC's role and methodology as a trial project, including trial/demonstration aspects of project selection and review, and integration of research findings and implementation experience into decision making.

To implement its environmental and social objectives, the SSTEC has been developed as a central element in a matrix of networked institutional relationships. These institutional interactions are examined, through a case study of the development of renewable energy-related initiatives at the SSTEC. The salient elements of these interactions relate to consultation and information flows. This is intended to facilitate an empirically based experimental approach to project planning, implementation and review, in terms of the integration of research and implementation experience. Thus, the role of institutional synergies in identifying and developing common features of successful eco-cities, and methodologies such as Key Performance Indicators (KPIs) is considered. In this way, the paper explores the complementary experimental and pluralist aspects of low-carbon planning at the SSTEC. Institutional and regulatory development at the SSTEC is evaluated in the context of other Chinese lowcarbon cities and other localised initiatives such as Green Counties and new energy 
demonstration cities. This evaluation draws on interviews with senior staff members at the SSTEC, and in specialist Chinese renewable energy institutions, as well as scholarly and other literature. The research findings relate firstly to interview evidence of information flows between the SSTEC and both state-related and non-government institutions involved in low-carbon development in Tianjin, and how this supports trial projects. The focus here is on SSTEC's participation in a conference on successful features of low-carbon industry parks. The second aspect of the research is discussion of examples of trial methodologies implemented at the SSTEC, in terms of project selection and review. The primary methodologies discussed are KPIs and full life-cycle analysis of project costs and impacts.

In terms of structure, Section 2 provides an overview of Chinese low-carbon city projects, together with related concepts such as new energy demonstration cities. The historical and theoretical sources of this approach to development are also summarised. Section 3 examines inter-institutional interactions involving the SSTEC, which constitutes a central element of the processes through which an evidence-based, experimental approach is implemented. Section 4 examines examples of trial and related empirical approaches at the SSTEC. The concluding section argues that while substantial implementation challenges face the SSTEC and similar Chinese projects, they are set to play a central role in scaling-up technologically and financially effective low-carbon solutions in Chinese urban development. Inefficiencies and failures identified through this experimental methodology can be utilised to develop best institutional and regulatory practice, to facilitate implementation of China's low-carbon model of sustainable urban development.

\section{CHINA'S LOW-CARBON CITIES AND RELATED CONCEPTS}

China's low-carbon cities, and similar projects, are arguably its largest trial projects, in terms of both the scale of individual projects and the number of projects involved. For example, the China National Renewable Energy Centre (CNREC) is responsible for project selection and management with respect to the goal of over 100 green counties and 100-200 New Energy Demonstration City (NEDC) projects set in China's twelfth five-year plan. This amounts to approximately one in six Chinese cities, Geng [1]. The KPI of the demonstration cities is the proportion of renewable energy sources in total energy consumption: at least $3 \%$ of its primary energy consumption by 2010 , and $6 \%$ by 2015 . In parallel, in 2010 , the National Development and Reform Commission (NDRC) established a demonstration program of five low-carbon pilot provinces and eight pilot low-carbon cities, aiming 'to decouple economic growth from fossil fuel use by shifting to an economy based on energy efficiency and renewable energy' Khanna et al. [2]. Their selection reflects their 'geographic, social and economic diversity and representativeness, existing foundation and/or preparation work in low-carbon development and demonstrated interest by the local regions to be a pilot location' Khanna et al. [2]. Other potentially overlapping initiatives include the Eco-city program of the Ministry of Environmental Protection (MEP), and the Eco-garden city program of the Ministry of Housing and Urban and Rural Development (MOHURD) [2].

The terms eco-cities and low-carbon cities, while not being identical in meaning, are sometimes used interchangeably, referring to the same city, $\mathrm{Wu}$ [3]. There is no official state definition of these terms, Zhou et al. [4]. Usage of these terms is most usefully correlated to the performance indicators set by the government agencies responsible for the pilot schemes under consideration. Moreover, the objectives of participating cities are variable within the overarching framework of environmentally sound/low-carbon development. For example, some eco-cities have been developed primarily to benefit from central government financial 
incentives, while others such as Caofeidian in northern China were developed to provide development opportunities following the decline of the local heavy industry. Others such as Guangming near Shenzhen have sought to develop high-tech enterprise clusters to build on the existing manufacturing strength in the low-carbon area, $\mathrm{Wu}$ [3]. For reasons of clarity, this paper refers to the SSTECs stated objectives and KPIs, rather than evaluating definitional approaches. (For discussion of definitional approaches see Caprotti [5].)

\section{THE SSTEC: INSTITUTIONAL FRAMEWORK AND INTERACTIONS}

The SSTEC is a central element in a matrix of networked institutional relationships, which are examined through a case study of the development of renewable energy-related initiatives. Consultation and information flows between institutions facilitate an empirical approach to SSTEC project planning, implementation and review, in terms of the integration of research and implementation experience. This section examines this process, focusing on an interview account of a workshop held to identify features of successful low-carbon industrial parks. To provide context, the institutional structure of the SSTEC is first detailed, in addition to its patterns of interaction with other institutional stakeholders.

The SSTEC has a close relationship with the independent municipality of Tianjin and the government of Singapore, as well as with the Chinese central government. A Sino-Singapore framework agreement governs its operations, coordinated by a Joint Steering Committee. Co-chaired by the Deputy Premiers of China and Singapore, it manages urban and environmental planning, including integrating renewable energy and water-recycling technologies. The lead Chinese ministry is the Ministry of Housing, Urban and Rural Development. Other Chinese institutions involved include the NDRC, the Ministry of Finance, the Ministry of Environment and the Municipality of Tianjin. The Sino-Singapore Tianjin Eco-City Investment and Development Co. Ltd., is the master developer of the eco-city. It is a 50-50 joint venture between a Chinese Consortium (the Tianjin Eco-City Investment and Development Co. Ltd), led by the Tianjin Economic Development Agency (TEDA) Investment Holding Co. Ltd., and a Singapore Consortium (Singapore Tianjin Eco-City Investment Holdings Pte. Ltd.), led by the Keppel Group Boon [6]. For reasons of scope, the interview with the Director of the SSTEC Economic Department, Xu Yan did not cover SSTEC cooperation with the Singapore government. (For information regarding the involvement of the Singapore government in the SSTEC, see the Singapore government's SSTEC web site [7]). Nor did the interview cover the involvement of other international stakeholders in Chinese low-carbon cities. These include the Institute for Sustainable Communities, the Joint US-China Collaboration on Clean Energy, the Sustainable Development Technology Foundation, the Low Carbon City China Alliance, the World Wildlife Fund, the UNDP, the EU and national governments including those of Switzerland and Norway Zhou et al. [4].

The SSTEC has broad-ranging environmental and social objectives that include: ' . . demonstrating the transformation of the current urban development mode in order to tackle climate change, save resources and energy, protect the environment, and achieve social harmony' [sic] Zhou et al. [4]. Its development plan covers an area of 30 square kilometres, with a projected population of 350,000 . The SSTEC has a KPI of $20 \%$ renewable energy by 2020, Xu Yan and Beaumler et al. [8]. The SSTEC committee connects directly to the Tianjin city government, as a 'dispatched department' (paiqu jigou), Xu Yan, Jia Lin translation [9]. SSTEC's commercial, environmental protection and finance departments all cooperate with the Information Department of the Tianjin government, and the Ministry of Construction Xu Yan [10]. The SSTEC is consulted in the process of Tianjin city energy planning, including 
through workshops and 'investigations', Xu Yan [10]. This process includes receiving drafts of policies and regulations, notice of whether SSTEC 'suggestions' have been accepted in relation to them, and the reasons for such decisions. Such consultation relates to how SSTEC operations are coordinated with the overall Tianjin energy planning, including consideration of SSTEC's 'obstacles and challenges' Xu Yan [10].

A workshop on Low-carbon industry parks was held on 9 January 2013 (the day prior to the interview), organised by the Tianjin division of the NDRC. Its purpose was to explore the common features of successful low-carbon industry parks, including relevant indicators. Xu Yan described two main groups of participants:

1. Those that are 'part of the government'. This includes the SSTEC and the Low-Carbon Centre of the Tianjin Economic Development Agency (TEDA) Industry Park, Xu Yan [10]. TEDA Low-carbon Center promotes low-carbon economy technology innovation and application through consulting for companies, and conducting an information service platform' (a monthly magazine) and the 'low-carbon economy commercial docking platform' (a 'business matching service'), TEDA web site [11].

2. Other participants included universities, research institutes, and transactional platforms such as the Wastewater Treatment Trading Centre. This was described as 'similar to the Chicago Trading Centre', and based on environmental quota system Xu Yan [10] (see also Stockholm Environment Institute web site [12]).

The interview illustrated how this pattern of institutional relationships is utilised to pool information on project implementation experience, for example in relation to developing environmental KPIs, and technology choice in the light of economic factors and local conditions. Hence, these institutional interactions are a central aspect of the development of the empirical methodologies discussed in the following section.

\section{EMPIRICAL/EXPERIMENTAL ASPECTS OF SSTEC PLANNING AND PROJECT IMPLEMENTATION}

This section discusses interview evidence of empirical approaches to planning and project implementation at the SSTEC, in terms of experimental, evidence-based approaches, including environmentally related statistical KPIs. These are used as benchmarks to implement the full life-cycle analysis of projects. The World Bank 'Sino-Singapore Tianjin Eco-City: A Case Study of an Emerging Eco-City in China' report indicates that SSTEC KPIs are 'broader and more advanced' than those of the MoHURD's eco-garden city standard and MEP's ecocity standard, particularly in relation to GHG emissions, renewable energy, solid waste recycling and water reclamation Beaumler et al. [8]. Low-emissions transportation and buildings and limits on domestic water consumption and waste generation are also included. KPIs set relevant central government targets include:

- KPI 5: Carbon emissions per unit GDP: $\leq 150$ tons $\mathrm{C}$ per one million US\$ GDP.

- KPI 7: Proportion of green buildings: $100 \%$.

- KPI 11: Per capita domestic waste generation: $\leq 0.8 \mathrm{~kg}$ per day (by 2013).

- KPI12: Proportion of green trips: $\geq 90 \%$.

- KPI 13: Overall solid waste recycling rate: $\geq 60 \%$ (by 2013).

- KPI 19: Renewable energy usage: $\geq 20 \%$.

- KPI 20: Water supply from non-traditional sources: $\geq 50 \%$. 
The tap water quality KPI is set at the Chinese national standard. Public green area per capita and noise pollution levels, are comparable to national eco-city standards. The KPI of $100 \%$ treatment to render domestic solid wastes non-toxic was already achieved in the Tianjin-Binhai New Area (TBNA) by 2009. Other KPIs depend on cooperative action in surrounding areas, such as ambient air quality and quality of water bodies, Beaumler et al. [8] and Zhou et al. [4].

According to Xu Yan, all SSTEC buildings must comply with 'green standards', and are subject to evaluation by the Ministry of Housing and Construction', Xu Yan [10]. (For Ministry of Housing and Construction targets for 'green buildings' see Chinese government web portal [13]). The SSTEC Green Building Evaluation Standard (GBES), was developed by the Tianjin Construction Commission with guidance from the Ministry of Housing, Urban, and Rural Construction. It specifies that energy use for heating residential buildings must be at least $65 \%$ less (50\% less for public buildings) than those constructed in the early 1980s. Heating/cooling systems and lighting and building appliances should use highly energy-efficient equipment and systems. Renewable energy must provide $10 \%$ of energy consumption in residential buildings, and $15 \%$ in public buildings. Implementation of these benchmarks will be critical to realising energy-related objectives as, due to the SSTECs economic structure, the share of energy consumed by buildings is much higher than the national average, and is projected to reach $40 \%$ by 2020, Beaumler et al. [8]. Xu Yan also indicated that full life-cycle evaluation of financial and environmental costs/impacts is implemented. For example, costbenefit analysis of construction of large-scale water storage reservoirs on the Singaporean model indicated that given the lower rainfall around Tianjin it was not genuinely eco-friendly. With regard to renewable energy technology choices, she said that a review is held after the conclusion of five projects, primarily on the basis of cost and suitability for local conditions, Xu Yan [10]. Geothermal energy and heat pumps will provide approximately 70\% of SSTEC's total renewable energy, primarily heating and cooling supply. Solar energy will account for most of the balance, providing domestic hot water and street lighting. Wind resources in and near SSTEC are inadequate for large-scale development, Xu Yan [10].

$\mathrm{Xu}$ Yan emphasised SSTEC's role in trialling new methods, 'for China and indeed the world'. She mentioned that outcomes are difficult to predict, as SSTEC remains in an early stage of development. Other challenges mentioned included a shortage of water, polluted soil, and that 'natural resources are not rich'. In fact, the SSTEC was established to confront such challenges, as its site was previously '. . . an industrial dumping ground for toxic waste, barren salt flats abutting one of the world's most polluted seas' Gaia Vince [14]. According to Tong Yen, head of SSTEC Development and Investment: 'In the past, so-called ecocities have been built in ecologically important areas or on useful arable land. We wanted to show that it is possible to clean up a polluted area and make it useful and liveable', Gaia Vince [14]. Given China's widespread environmental pollution, these challenges highlight the utility of the SSTEC as an experimental project. Environmentally related KPIs and full life-cycle impact analysis are central to the SSTECs implementation and review process, informing decisions about continuation and amendment of projects. Thus, an empirically based experimental approach is implemented both at the stage of project selection and review.

\section{CONCLUSION}

A 2012 World Bank report on Chinese eco-cities reached a favourable conclusion regarding the SSTEC's 'ambitious KPIs, including explicit ones on carbon intensity', World Bank [15]. Indeed 
it suggested that: 'The indicators that have been articulated for cities such as the Caofeidian ecocity or the Sino-Singapore eco-city are generally more advanced and could guide any revision of the national standards' World Bank [15]. Other positive features identified were planning for 'high population density, transit-orientated development, a mixed land-use plan, an explicit local working/living ratio, and the provision of affordable housing — all necessary conditions for ecoand low-carbon city development' World Bank [15]. It also identified '. . . the need to avoid the mistakes made in other countries that embarked on large-scale "new town" experiments where too much was built too quickly', World Bank [15]. Given that several SSTEC KPIs are set to be achieved by 2020 , it may be that detailed implementation progress will be assessed and published by that time. At least until recently, the SSTEC was still very much a work in progress, with relatively little population or economic activity occurring, Caprotti [5]. As the World Bank report notes, the SSTEC needs 'to complement technological solutions with economic incentives, to manage the balance between commercial and public interests, to ensure affordability to create socially inclusive, vibrant communities', World Bank [15].

Whether this and other SSTEC objectives can be achieved represents a challenge not underestimated by SSTEC staff such as Xu Yan. Whether the SSTEC is ultimately a successful pilot naturally depends on what benchmarks are used. While achieving the KPIs are the most obvious benchmarks, they are not the only criterion for success. Some of the KPIs such as handling of solid wastes have already been achieved, while others such as renewable energy application and green buildings are readily achievable by independent SSTEC initiatives. Others such as air and water quality depend on the cooperative action in surrounding areas. Clearly, the achievement of the KPIs will be more practically significant in the event that the SSTEC is able to attract its target population and associated economic activity. This is less straightforward than the achievement of the KPIs in themselves, and progress to date does not appear rapid. An alternative benchmark for success is whether technologies, urban planning initiatives and low-carbon strategies such as the KPIs and green building standards trialled at the SSTEC, prove widely applicable and effective in China. It is in the nature of experimental projects that some will succeed and others will fail. While trial projects at the eco-cities could certainly constitute expensive failures, they may nonetheless play a significant role in learning-by-doing. Given the sheer number, totalling well into the hundreds of Chinese eco- and low-carbon cities, it is inevitable that there will be some failures, some notable successes and some in between. Like much else in the Chinese economy, the overall scale of long-term state support can play a significant role in determining market outcomes. Like many sectors in Chinese industry, longer-term success may come at a considerable cost, in terms of the creation of oversupply and subsequent shake-outs. State support including large-scale subsidies has arguably been a factor in the build-up of excess capacity in solar PV cell manufacturing and other sectors, such as ship building and automotive manufacturing, Bayileyev et al. [16] and Dodson [17]. This could prove to be the case in terms of presently empty SSTEC real estate, and at the entire eco-city level. Conversely, the SSTEC may be on the cusp of successfully demonstrating best practice planning and implementation for Chinese and indeed global eco-cities.

Despite these uncertainties, the research presented in this paper has presented cogent evidence of experimental approaches to low-carbon planning and implementation at the SSTEC. Environmentally related KPIs and full life-cycle impact analysis are central to this process, forming the basis for decisions about project selection, continuation and amendment. Thus, specific technologies and projects such as solar energy, water harvesting green buildings are reviewed on a cost-benefit basis over their entire life cycle, in terms of their effectiveness in 
achieving the SSTEC's KPIs. This methodology is evidence-based, and allows for a degree of flexibility for experimentation to discover the most cost-effective means of achieving the KPIs. This approach, moreover, is explicitly adopted on a trial basis, with successful outcomes to be scaled-up on a national basis. This paper's research demonstrated that pluralistic institutional synergies are a critical aspect of this empirically based experimental approach, in that learning-by-doing is leveraged across a broad range of stakeholders through collaborative communication. Interview evidence of the Tianjin workshop on successful features of low-carbon industry parks provided the primary example of the operation of this process. In this way, the research indicated that evidence-based planning is central to SSTEC trial projects. While the SSTEC faces major challenges, the evidence of this paper indicates that whatever the outcome, the experience gained will be utilised in an empirical way to guide further project development.

\section{REFERENCES}

[1] Geng, D, Review and Outlook on China Renewable Energy. Power point for Chinese Renewable Energy Industry Association, 25 February 2014, available at: http://jref. or.jp/images/pdf/20140225/Geng_Dan_REvision2014_Session1_2.pdf

[2] Khanna, N., Fridley, D. \& Hong, L., Evaluating China's pilot low-carbon city initiative: national goals and local plans. Report for Lawrence Berkeley National Laboratory, USA, pp. 3-4, March 2013, available at: https://publications.lbl.gov/islandora/object/ ir\%3A158764/datastream/PDF/view

[3] Wu, F., China's eco-cities. Geoforum, 2(43) pp. 169-171, 2012. http://dx.doi.org/10.1016/j.geoforum.2011.08.001

[4] See Zhou, N., He, G. \& Williams, C., China's development of low-carbon eco-cities and associated indicator systems. Report LBNL-5873E, China Energy Group Energy Analysis \& Environmental Impacts Department, Ernest Orlando Lawrence Berkley National Laboratory, p. 1, July 2012, available at: http://china.lbl.gov/sites/all/files/china_ecocities_indicator_systems.pdf

[5] Caprotti, F., Critical research on eco cities: a walk through the Sino-Singapore Tianjin Eco City, China. Cities, 36, pp. 10-17, 2014, available at: http://www.sciencedirect. com/science/article/pii/S0264275113001327 http://dx.doi.org/10.1016/j.cities.2013.08.005

[6] Boon, G.C., (CEO of SSTEC Investment and Development Co. Ltd), Developing a City of the Future: Sino-Singapore Tianjin Eco-City, 2008, available at: http://www.siww.com. sg/pdf/08_Developing_a_city_of_the_future_Sino_singapore_Tianjin_Eco_city.pdf

[7] Singapore government's SSTEC, available at: http://www.tianjinecocity.gov.sg/

[8] Baeumler, A., et al., Sino-Singapore Tianjin Eco-City: A Case Study of an Emerging Eco-City in China. World Bank Technical Assistance Report No. 59012, November 2009, Box 8.1: SSTEC Project National-level Coordination, Table 1.3 Key Performance Indicators for SSTEC, pp. 12. See also Annex 1 Key Performance Indicators (KPIs) for SSTEC, pp. 119, available at: http://www-wds.worldbank.org/external/default/WDSContentServer/WDSP/IB/2011/01/17/000333037_20110117011432/Rendered/PDF/ 590120WP0P114811REPORT0FINAL1EN1WEB.pdf

[9] Jia Lin translator, interview with Xu Yan.

[10] Interview with Xu Yan, offices of the Economic Department of the SSTEC.

[11] Tianjin Economic Development Agency, available at: http://www.ecoteda.org/english/ list.php?catid=935 
[12] Chicago Climate Exchange, Stockholm Environment Institute web site. (The CCX was discontinued on 1 January 2011), available at: http://www.co2offsetresearch.org/policy/ CCX.html

[13] China Set to Construct More Green Buildings, Chinese government web portal, 7 May 2012, available at: http://www.china.org.cn/business/2012-05/07/content_25317043. htm

[14] Gaia Vince, China's Eco-cities: Sustainable Urban Living in Tianjin. BBC Future Education (online), 3 May 2012, available at: http://www.bbc.com/future/story/20120503sustainable-cities-on-the-rise

[15] Baeumler, A., Ijjasz-Vasquez, E. \& Mehndiratta, S., (eds) Sustainable Low-Carbon City Development in China. World Bank Report p. 47, 2012, available at: http://siteresources. worldbank.org/EXTNEWSCHINESE/Resources/3196537-1202098669693/46355411335945747603/low_carbon_city_full_en.pdf

[16] Bayaliyev, A., Kalloz, J. \& Robinson, M., China's solar policy: subsidies, manufacturing overcapacity \& opportunities. Research paper for the George Washington University Trachtenberg School of Public Policy and Public Administration, Masters in Public Policy and Public Administration Capstone Project, pp. 18-26, December 23 2011, available at: http://solar.gwu.edu/Research/ChinaSolarPolicy_BayaKallozRobins.pdf

[17] Dodson, B., China Fast Forward: The Technologies, Green Industries and Innovations Driving the Nation's Future, John Wiley \& Sons, pp. 65-69, 2012. 